\title{
Rancangan Sistem Pengendalian Manajemen Menggunakan Metode Six Sigma Di Digital Innovation Lounge (Dilo) Bandung
}

\author{
Nisha Sofiani, Annisa Suci Riani2 \\ Politeknik STIA LAN Bandung, Indonesia ${ }^{1,2}$
}

$\varpi$ Corresponding Author:

Nama Penulis: Nisha Sofiani

E-mail: nishasofiani@poltek.stialanbandung.ac.id

\begin{abstract}
A management control system is required to ensure the organization's continuity. To increase customer satisfaction, quality standards must be considered. The management control system at the Digital Innovation Lounge (DILo) Bandung still needs to be improved. The Six Sigma method is used to develop a strategy for strengthening the management control system's quality. This study employs a descriptive qualitative method, with primary data derived from interviews and observations. According to the findings of this research, management control implementation is still ineffective. This is due to a lack of understanding about the importance of management control, as well as insufficient supervision, which is causing issues. The recommended improvement in this case is to create business process standards so that all activities have clear targets related to business processes, training, and employee performance. Furthermore, supervision is required to ensure that these improvements are implemented so that they can affect business processes.
\end{abstract}

Keywords: Management Control System, Six Sigma

\begin{abstract}
Abstrak: Sistem pengendalian manajemen diperlukan untuk memastikan keberlangsungan dari organisasi. Standar kualitas perlu diperhatikan untuk meningkatkan kepuasan pelanggan. Digital Innovation Lounge (DILo) Bandung masih memerlukan peningkatan dalam hal sistem pengendalian manajemen. Metode Six Sigma digunakan untuk membentuk strategi dalam meningkatkan kualitas dari sistem pengendalian manajemen. Penelitian ini menggunakan metode kualitatif deskriptif, dimana data primer yang digunakan berupa data kualitatif dari hasil wawancara dan observasi. Penelitian ini menunjukkan bahwa pelaksanaan pengendalian manajemen masih kurang efektif. Faktor yang menyebabkan hal tersebut adalah belum ada kesadaran mengenai pentingnya pengendalian manajemen, serta pengawasan yang belum optimal sehingga menimbulkan permasalahan. Dalam hal ini perbaikan yang direkomendasikan adalah merancang standar proses bisnis agar seluruh kegiatan memiliki target yang jelas berkaitan dengan proses bisnis, pelatihan dan kinerja karyawan. Selain itu, perlu juga dilakukan pengawasan untuk memastikan perbaikan tersebut diterapkan sehingga dapat memberikan perubahan terhadap proses bisnis.
\end{abstract}

Kata Kunci: Sistem Pengendalian Manajemen, Six Sigma 


\section{PENDAHULUAN}

Perkembangan zaman dan era globalisasi mengubah situasi perekonomian sehingga perusahaan perlu menyesuaikan diri dengan kondisi tersebut. Sistem pengendalian manajemen diperlukan sebagai salah satu strategi pencapaian tujuan jangka pendek dan jangka panjang di organisasi. Menurut Anthony dan Govindrajan (dalam Tjakrawala, 2005), Sistem pengendalian manajemen adalah proses yang memotivasi dan menginspirasi orang-orang dalam suatu organisasi untuk melakukan kegiatan yang mengarah pada pencapaian tujuan organisasi. Artinya sistem pengendalian manajemen dalam pelaksanaannya akan mengarah kepada tujuan yang hendak dicapai perusahaan serta dapat mengarahkan seluruh proses bisnis organisasi sesuai rencana dan tujuan awal organisasi yang telah ditetapkan. BUMN atau badan usaha milik negara, yaitu pelaku ekonomi yang seluruh atau sebagian kekayaannya dikuasai oleh negara. Telkom merupakan perusahaan yang bergerak dibidang jasa teknologi informasi dan komunikasi juga jaringan telekomunikasi di Indonesia. Bentuk perhatian PT. Telkom Indonesia yaitu menciptakan sebuah program tanggung jawab sosial. Tanggung jawab sosial terhadap masyarakat yang dimiliki oleh Telkom melalui paradigma "Telkom ada untuk Indonesia, tumbuh dan berkembang bersama-sama masyarakat Indonesia" yang diyakini Telkom dengan cara meningkatnya kesejahteraan masyarakat maka secara tidak langsung akan berdampak besar dalam keberlangsungan usaha Telkom. Salah satu bentuk program tanggung jawab sosial dari PT. Telkom yaitu dengan menghadirkan Digital Innovation Lounge (DILo).

Digital Innovation Lounge (DILo) merupakan sebuah kamp kreatif yang diinisasi oleh Telkom Indonesia dan Masyarakat Industri Kreatif Teknologi Informasi dan Komunikasi Indonesia (MIKTI). DILo atau Digital Innovation Lounge merupakan wadah atau tempat talenta, start-up dan komunitas bekerja sama dalam membangun mimpi dalam dunia digital melalui program pre-startup development, digital professional talent dan digital community development. DILo merupakan perusahaan yang menawarkan pelatihan kepada UMKM untuk masuk ke dalam platform digital.

DILo dibentuk guna menciptakan dan meningkatkan kualitas serta kuantitas bibit digitalpreneur sekaligus membantu pemberdayaan masyarakat dan komunitas 
yang ada di Indonesia. Menjadi anggota DILo dapat memberikan berbagai keuntungan yaitu dapat menikmati berbagai fasilitas yang disediakan oleh DILo seperti minicafe, coworking, ruang rapat, ruang kelas dan akses internet yang tinggi. Saat ini di Digital Innovation Lounge (DILo) masih terdapat hal yang dapat ditingkatkan terkait dengan pengendalian manajemen. Hal tersebut dapat dilihat dari fenomena yang terjadi yaitu DILo sendiri belum menyadari peran penting pengendalian manajemen sepenuhnya. Terdapat beberapa permasalahan seperti pekerjaan yang tidak langsung diselesaikan, pengawasan operasional yang belum memadai, kegagalan menjalankan perintah hal ini terbukti dari adanya karyawan yang belum bisa menjalankan perintah yang diberikan secara baik sehingga kegiatan pelatihan tidak berjalan baik. Permasalahan tersebut didapatkan saat melakukan observasi dan wawancara kepada seluruh pihak yang terlibat. Selain itu, kurangnya komunikasi antara karyawan dan pimpunan perihal pekerjaan juga berkontribusi terhadap permasalahan tersebut. Maka, perbaikan untuk meningkatkan kualitas kinerja perlu dilakukan.

Peningkatan kualitas dapat menjadi hal yang sulit untuk diidentifikasi dan diukur tanpa kualitas sistem biaya yang efektif. Kualitas dari produk dan jasa tidak hanya fokus pada keluaran namun juga dalam kualitas dari keseluruhan proses bisnis (Love dan Li, 2000). Six sigma merupakan alat yang dapat digunakan dalam pengendalian kualitas di organisasi. Six sigma merupakan metode yang awalnya digunakan di industri manufaktur untuk mengurangi limbah dari proses produksi yang kemudian dikembangkan dan saat ini banyak diimplementasikan dalam berbagai jenis industri termasuk dalam industri jasa (Stewart dan Spencer, 2006; Han et.al. 2008). Six Sigma dianggap sebagai strategi bisnis kuat yang menggunakan metode perbaikan berkelanjutan yang terstruktur dengan baik untuk mengurangi variabilitas proses dan menghilangkan pemborosan dalam proses bisnis menggunakan aplikasi alat dan teknologi yang efektif (Banuelas et.al., 2005). Tujuan utama dari program Six Sigma adalah untuk menciptakan nilai yang lebih tinggi dari produk dan layanan perusahaan di mata pelanggan. Tujuan dari penelitian ini adalah untuk merancang sistem pengendalian manajemen di lingkungan DILo guna meningkatkan kualitas dan meminimalisir kesalahan. 


\section{METODE PENELITIAN}

Penelitian ini dilakukan untuk meningkatkan kualitas di lingkungan DILo. Six Sigma digunakan untuk meningkatkan dan mengendalikan kualitas. Penelitian ini menggunakan pendekatan kualitatif deskriptif, dimana peneliti akan menganalisis berupa deskriptif dengan kata-kata tidak menggunakan angka. Menurut Sukmadinata (2006) penelitian deskriptif adalah suatu bentuk penelitian yang bertujuan untuk menjelaskan fenomena yang ada, baik yang alami maupun buatan. Fenomena-fenomena tersebut dapat berupa bentuk, kegiatan, karakteristik, dan lain-lain, serta perbedaan antara fenomena yang satu dengan yang lainnya.

Teknik pengumpulan data menurut Sugiyono (2012 merupakan langkah paling strategis dalam penelitian, karena tujuan utama penelitian adalah mengumpulkan data. Penelitian ini menggunakan beberapa teknik pengumpulan data yaitu wawancara, observasi dan studi pustaka. Instrumen penelitian adalah alat pengumpulan data yang memudahkan untuk menyelidiki hasil yang diperoleh. Teknik dan instrument pengumpulan data yang digunakan yaitu: (1) wawancara dengan menggunakan instrumen pedoman wawancara; (2) Observasi dengan instrumen yang digunakan adalah lembar observasi; (3) studi pustaka

Data yang diperoleh dalam penelitian ini berasal dari data primer dan sekunder. Menurut Sunyoto (2013), data primer adalah data asli yang peneliti sendiri kumpulkan untuk memberikan jawaban konkrit terhadap permasalahan yang ada dalam penelitian. Data primer diperoleh dari hasil observasi lapangan dan wawancara dengan manager DILo Bandung, admin DILo Bandung, tim DILo pusat dan peserta kegiatan pelatihan. Data sekunder adalah sumber data yang tidak memberikan data secara langsung kepada peneliti, misalnya seperti melalui orang lain atau bahkan lewat dokumen (Sugiyono, 2016). Sumber data sekunder dalam penelitian ini diperoleh dari studi pustaka seperti karya ilmiah, internet dan sumber-sumber lainnya.

\section{HASIL PENELITIAN}

Six Sigma merupakan suatu metode yang menyeluruh dan fleksibel untuk meningkatkan, mempertahankan dan meminimalkan kesalahan untuk mencapai kesuksesan proses bisnis (Pande, 2002). Six sigma banyak digunakan untuk meningkatkan kualitas dari produk atau jasa dalam berbagai jenis organisasi. 
Terdapat lima langkah dalam penerapan Six Sigma yang perlu dilakukan yaitu Define, Measure, Analysis, Improve dan Control (DMAIC). Selain itu, terdapat pula diagram SIPOC (Supplier, Input, Process, Output, dan Customers) yang merupakan salah satu alat yang turut digunakan dalam penerapan Six Sigma.

\subsection{Tahap Penemuan Masalah (Define)}

Identifikasi masalah dalam tahap ini dilakukan melalui metode wawancara dan observiasi dengan menggunakan SIPOC. Hasil dari proses tersebut tercantum pada Tabel 1 berikut. Tabel SIPOC tersebut menjadi patokan dalam pelaksanaan pengendalian manajemen di DILo terutama pada proses bisnis serta rancangan perbaikan yang akan ditetapkan.

Diagram pareto juga digunakan untuk menemukan masalah yang dapat membantu dalam proses perbaikan dan pengendalian manajemen. Kemudian ditemukan nilai akibat dari permasalahan yang paling besar yaitu pada poin tidak adanya standar pengendalian sebesar $42 \%$. Hasil dari diagram tersebut dapat dilihat pada Gambar 1.

Tabel 3.1 SIPOC DILo

\begin{tabular}{l|l|l|l|l}
\multicolumn{1}{c}{ Supplier } & \multicolumn{1}{c}{ Input } & Process & \multicolumn{1}{c}{ Output } & Customer \\
\hline - Asosiasi & $\bullet$ Pemateri & $\bullet$ Pelatihan & $\bullet$ Penggunaan & $\bullet$ UMKM \\
Pengusaha & (Fasilitator & penggunaan & tools UI-UX & yang ingin \\
- Kampus/Unive & \& Informan) & tools UI-UX & pada produk & belajar \\
rsitas & $\bullet$ Pendanaan & (digital) & UMKM & tentang \\
- Unpad & (CSR Telkom & $\bullet$ Pelatihan & $\bullet$ Desain & digitalisasi \\
(Gedung) & dan Mikti) & branding & aplikasi dan & \\
Balemotekar & & product & pengujian & \\
& & (digital) & prototipe & \\
& & $\bullet$ Pelatihan & produk & \\
& & coding & UMKM & \\
& & & - Pemasaran & \\
& & & digital produk & \\
& & & UMKM & \\
& & & - Pembuatan & \\
& & & website & \\
& & & UMKM & \\
& & &
\end{tabular}

Sumber : Data primer diolah, 2021 


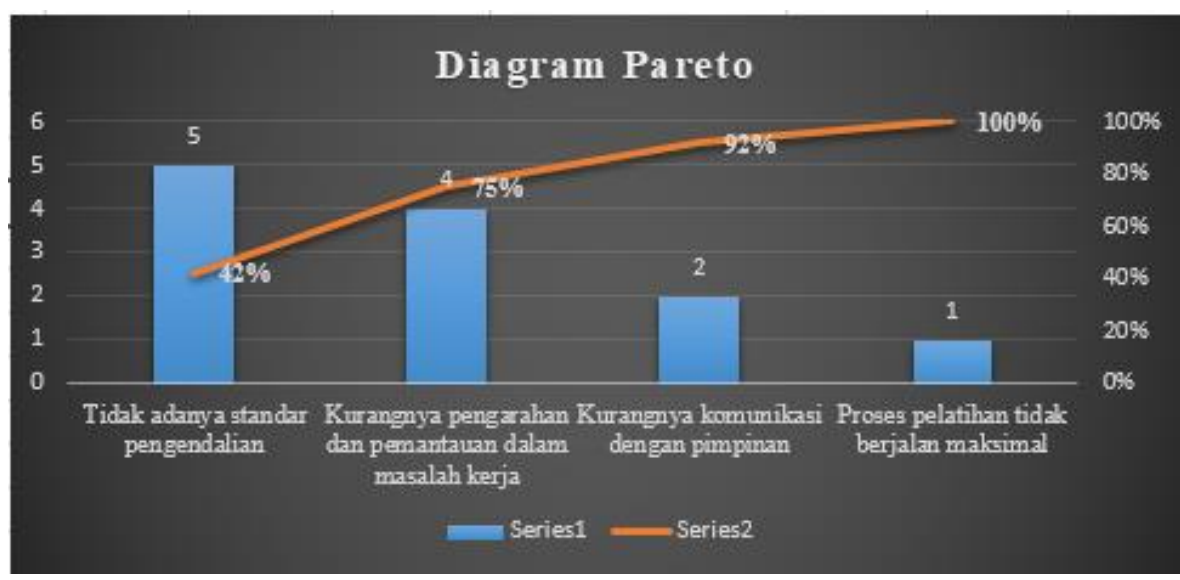

Gambar 3.1. Diagram Pareto

\subsection{Tahap Pengukuran (Measure)}

Sejauh ini belum ada patokan ukuran keberhasilan proses bisnis yang dijalankan oleh DILo karena DILo belum memiliki standar bisnis sehingga target yang harus dicapai oleh DILo belum ada. Saat ini DILo belum mencapai ukuran keberhasilan kegiatan pelatihan hal ini dibuktikan karena saat dilakukan observasi selama kegiatan diadakan online peserta semakin berkurang. Saat dilakukan wawancara kepada peserta yang mengikuti pelatihan mereka tidak sepenuhnya memahami materi, akibatnya pelatihan yang diberikan oleh DILo tidak berjalan maksimal.

\subsection{Tahap Analisis (Analyze)}

Tujuan dari analisis adalah menemukan berbagai formulasi dalam pemecahan masalah yang ada di dalam proses bisnis dan akan dirumuskan berbagai solusi untuk meningkatkan proses bisnis tersebut. Pada tahap ini peneliti menggunakan diagram sebab-akibat (cause and effect diagram). Diagram tersebut dibangun untuk melihat apa yang menjadi akar permasalahan dengan melihat empat aspek, yaitu aspek manusia, metode, lingkungan dan ukuran.

Dari aspek manusia, hal yang penyebab permasalahan adalah; (I) pimpinan tidak menyadari peran penting dari standari proses bisnis; (II) pimpinan dan karyawan jarang melakukan evaluasi kinerja serta kegiatan pelatihan; (III) pimpinan belum menyadari peran pengendalian manajemen yang terlihat dari tidak adanya penerapan pengendalian keseluruhan kegiatan proses bisnis. Dari aspek lingkungan hal yang menjadi penyebab permasalahan adalah lingkungan yang kurang nyaman (I). Dari aspek ukuran yang menjadi penyebab 
permasalahan adalah hanya menilai dari keberhasilan keseluruhan proses bisnis (I). Serta dari aspek metode yang menjadi penyebab permasalahan adalah tidak adanya metode evaluasi yang digunakan, seluruh proses bisnis berjalan tanpa acuan atau standar. Diagram tersebut dapat dilihat pada Gambar 2.

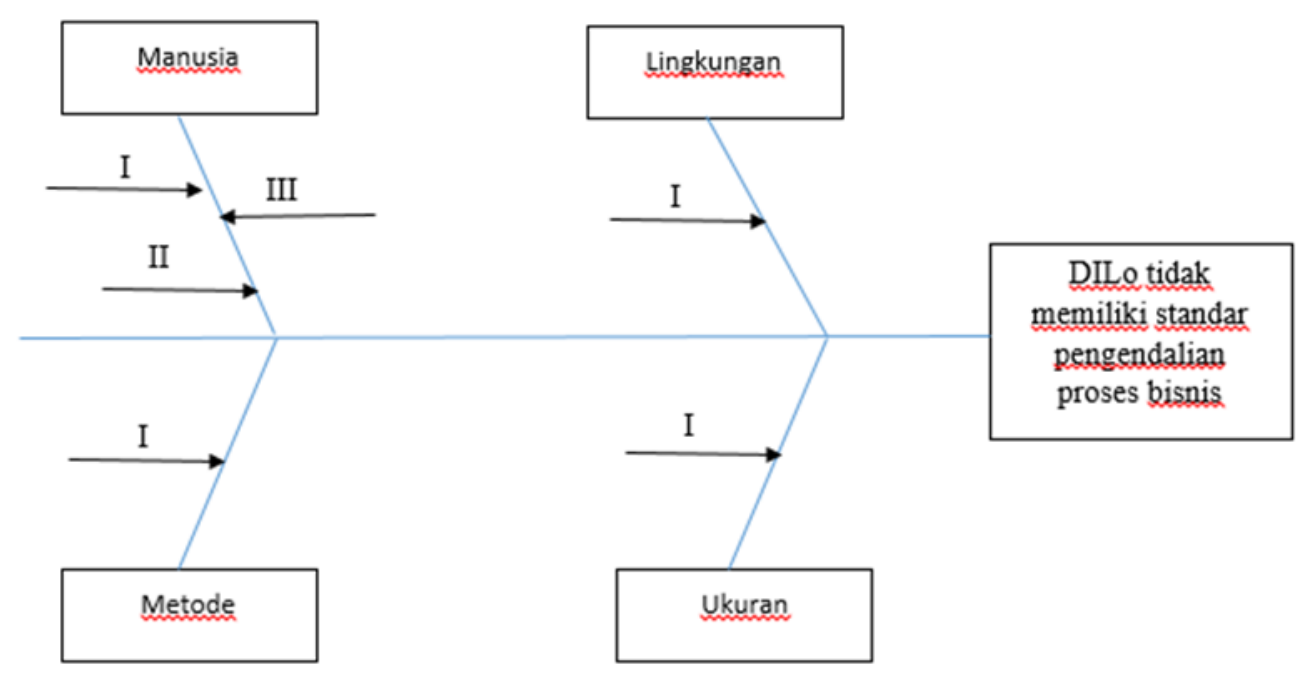

Gambar 3.2 Diagram Pareto

\subsection{Tahap Peningkatan (Improve)}

Perlu adanya pemahaman yang lebih tentang apa itu pengendalian manajemen terutama fungsinya terhadap kegiatan DILo dan perlu adanya pengawasan terhadap seluruh proses bisnis yang dijalankan. Untuk melakukan pengawasan terhadap seluruh proses bisnis yang diharapkan dapat diikuti oleh karyawan DILo, maka peneliti merekomendasi perbaikan dengan membuat standar proses bisnis agar seluruh kegiatan yang berlangsung tetap terkontrol dan berjalan sesuai dengan tujuan.

\section{Tabel 3.2 Standar Proses Bisnis}

\section{Standar Proses Bisnis}

1. Tidak ada target jumlah kegiatan pelatihan per-bulan

2. Tidak ada target jumlah minimum peserta dalam

Latar Belakang setiap kegiatan pelatihan

3. Perlu ada evaluasi kegiatan pelatihan

4. Ketepatan dan kualitas kerja yang masih perlu ditingkatkan

Tujuan

1. Menyusun target kegiatan pelatihan dalam sebulan beserta target jumlah peserta minimum

2. Pengaturan pola kerja karyawan agar lebih efektif 
dan efisien

3. Melaksanakan evaluasi untuk mendapatkan umpan balik dari kegiatan

Ruang Lingkup

Tanggung Jawab Unit Kerja Terlibat

Prosedur Pelaksanaan
Tugas dan tanggung jawab anggota organisasi dalam menjalankan proses bisnis Pimpinan DILo

Administrasi dan Public Relation

1. Kegiatan pelatihan dilaksanakan minimal $4 \mathrm{kali}$ dengan jumlah peserta 30 orang

2. Pengajuan dilaksanakan paling akhir tanggal 25 setiap bulan

3. Laporan kegiatan dilaporkan paling lambat satu minggu setelah kegiatan melalui googledrive

4. Berkas dan laporan yang akan diunggah diperiksa Kembali

5. Perusahaan wajib melaksanakan evaluasi terkait hasil, kinerja dan kegiatan proses bisnis

Rekaman Laporan Kegiatan

\subsection{Tahap Pengawasan (Control)}

Pengawasan diperlukan untuk memastikan perubahan yang disusun dapat diterapkan secara kontinu dalam sistem sehingga dampak yang diinginkan dapat tercapai. Beberapa hal yang dapat dilakukan sebagai bentuk pengawasan adalah:

a) Pengawasan terhadap keseluruhan proses bisnis DILo;

b) Pengawasan terhadap pelaksanaan prosedur kerja oleh karyawan;

c) Pemeriksaan terhadap fasilitas yang digunakan sebelum pelatihan;

d) Melaksanakan evaluasi terhadap kinerja dan proses bisnis yang dilaksanakan;

e) Melakukan survei terhadap kepuasan dalam pelaksanaan pelatihan kepada peserta.

\section{PEMBAHASAN}

Berdasarkan hasil wawancara dan observasi, salah satu faktor yang menjadi penyebab pelaksanaan pengendalian manajemen belum optimal adalah karena organisasi belum sepenuhnya memahami pentingnya pengendalian manajemen. Hal tersebut ditunjukkan dalam tidak seluruh kegiatan dilakukan pengendalian sehingga pengendalian yang diterapkan belum maksimal seperti yang dikatakan oleh pimpinan DILo bahwa mereka membuat laporan kegiatan namun laporan tersebut tidak digunakan untuk evaluasi. 
Adanya pengabaian manajemen dalam urusan pekerjaan, pengawasan operasional yang belum memadai dan kegagalan menjalankan perintah terbukti dari adanya karyawan yang belum bisa menjalankan perintah yang diberikan secara baik dan pada akhirnya menimbulkan beberapa masalah yang disebabkan dari belum efektifnya pengendalian manajemen seperti: (1) Kurangnya komunikasi dengan pimpinan DILo perihal pekerjaan dan proses bisnis DILo; (2) Kurangnya pengarahan dan pemantauan dalam lingkungan kerja DILo seperti dalam membuat laporan bisnis yang masih terdapat beberapa kesalahan; (3) Kegiatan proses pelatihan yang tidak berjalan maksimal karena persiapan yang belum matang; (4) Tidak adanya target standar pengendalian dalam pelaksanaan proses bisnis DILo Bandung.

Untuk memperbaiki permasalahan pengendalian manajemen pada proses bisnis DILo Bandung, konsep Six Sigma dapat dijadikan sebagai upaya untuk melakukan analisa terkait permasalahan tersebut. Dalam Six Sigma tersebut dilakukan identifikasi permasalahan yang kemudian dianalisa dan disusun rancangan perbaikan. Dalam hal ini perbaikan yang direkomendasikan adalah menyusun standar proses bisnis agar seluruh kegiatan memiliki target yang jelas berkaitan dengan proses bisnis, pelatihan dan kinerja karyawan. Selain itu, perlu juga dilakukan pengawasan untuk memastikan perbaikan tersebut diterapkan sehingga dapat memberikan perubahan terhadap proses bisnis.

\section{KESIMPULAN}

Pengendalian manajemen dibutuhkan pada proses bisnis DILo. Faktor yang menyebabkan pelaksanaan pengendalian manajemen belum optimal adalah belum adanya kesadaran tentang peran penting dari pengendalian manajemen. Adanya pengabaian manajemen seperti pekerjaan yang tidak langsung diselesaikan, pengawasan operasional yang belum memadai dan kegagalan menjalankan perintah. Pada akhirnya hal tersebut menimbulkan beberapa masalah kegiatan yang disebabkan dari belum efektifnya pengendalian manajemen.

Konsep Six Sigma digunakan sebagai upaya untuk menyelesaikan permasalahan pengendalian manajemen tersebut. Dari proses yang terdiri dari DMAIC tersebut, disusun suatu strategi disusun untuk menyelesaikan permasalahan. Dalam hal ini perbaikan yang direkomendasikan adalah menyusun standar proses bisnis agar 
seluruh kegiatan memiliki target yang jelas berkaitan dengan proses bisnis, pelatihan dan kinerja karyawan. Pengawasan juga turut diperlukan untuk memastikan perbaikan tersebut diterapkan sehingga dapat memberikan dampak positif terhadap proses bisnis di lingkup tersebut.

\section{REFERENSI}

Anthony, R.N dan Govindrajan, V. 2005. Management Control System. Edisi II. Jilid 1 dan 2. Jakarta: Salemba Empat.

Bakti, C.S. 2018. Penerapan Metode Six Sigma dan Perbaikan Kerja Pada Pengendalian Kualitas Sepatu CV. Cir. Jurnal STT Yuppentek. Vol 9 (1). p. 49-57.

Bañuelas, R.; Antony, J.; Brace, M. 2005. An application of Six Sigma to reduce waste, Quality and Reliability Engineering International 21(6): 553-570.

Evans, J. R., dan Lindsay, W.M. 2007. An Introduction Six Sigma \& Process Improvement. Jakarta: Salemba Empat.

Gaspersz, V. 2002. Pedoman Implementasi Program Six Sigma. Jakarta: PT. Gramedia Pustaka Utama.

Gaspersz, V. 2005. Total Quality Management. Jakarta: PT. Gramedia Pustaka Utama.

Han, S. H.; Chae, M. J.; Im, D. S.; Ryu, H. D. 2008. Six Sigma Based approach to improve performance in construction operations, Journal of Management in Engineering ASCE 24(1): 21-31

Love, E. D. P; Li, H. 2000. Quantifying the causes and costs of rework in construction, Construction Management and Economics 18(4): 479-490.

Stewart, R. A.; Spencer, C. A. 2006. Six Sigma as a strategy for process improvement on construction projects: a case study, Construction Management and Economics 24(4): 339-348.

Sugiyono. 2012. Memahami Penelitian Kualitatif. Bandung: Bandung: Alfabeta.

Sugiyono. 2016. Metode Penelitian Kuantitatif Kualitatif dan Kombinasi (Mixed Methods). Bandung: Alfabeta.

Sukmadinata, N.S. 2010. Metode Penelitian Pendidikan. Bandung: PT. Remaja Rosdakarya.

Sunyoto, D. 2013. Metodologi Penelitian Akutansi. Bandung: PT. Refika Aditama Anggota Ikapi.

Triantoro, Y. dan Abdul, F.W. 2021. Perbaikan Warehouse Business Process Dengan Metode Lean Six Sigma Di PT. XYZ. Jurnal Manajemen Logistik. Vol 1 (1). p. 5360.

Wahyudi, M.R. 2020. Implementasi Six Sigma Untuk Perbaikan Proses Bisnis Dan Perancangan Prosedur Operasional Standar: Studi Kasus Pada Nasi Krawu Bu Tiban Gresik. Jurnal Teknik ITS. Vol 9 (2). p. 137-142. 